\section{Association of Oral Lichen Planus and Electrocardiographic P-Wave Dispersion - An Original Research}

\author{
R. Aditi', S. Sathasivasubramanian², M. Emmanuel Bhaskar ${ }^{3}$
}

\author{
'Department of Oral Medicine and \\ Radiology, Sri Sai College of Dental \\ Surgery, Vikarabad, Telangana, India \\ ${ }^{2}$ Department of Oral Medicine and \\ Radiology, Sri Ramachandra University, \\ Porur, Chennai, Tamil Nadu, India \\ ${ }^{2}$ Department of General Medicine, \\ Sri Ramachandra University, Porur, \\ Chennai, Tamil Nadu, India
}

Correspondence: R. Aditi, \#201, Vindhyachal Apartments, 104-35 Masabtank, Hyderabad, 500028, Telangana, India. Tel: +91-80-0843-5760. e-mail: aditiramesh2804@gmail.com

Key Words: atrial fibrillation, oral lichen planus, inflammation, $\mathrm{P}$-wave dispersion.

\section{Introduction}

Lichen planus (LP), was first described by Wilson in 1869, as an inflammatory disease of the skin and mucosa (1) Though it is of unknown etiology, alterations in cell mediated immunity are considered to be important (2) Krutchkoff et al. (3) reported that patients with oral lichen planus (OLP) have a higher tendency to develop carcinomas compared to individuals without OLP. Literature reviews have revealed an association of LP with various systemic diseases like autoimmune diseases (4), internal malignancies (4), hepatitis $C$ virus (4), chronic liver diseases (5), viral infections (4) and factors like stress/anxiety (4), and others. It is also possibly associated with diabetes mellitus (5), hypertension (5), dyslipidemia (4) and also a risk of atrial fibrillation (6) One study in the past has expressed relationship between cutaneous LP and an increase in P-wave Dispersion (PWD) which indicates a risk of atrial fibrillation (6) However, association of oral LP with electrocardiographic changes are rarely found in the literature.

LP is considered to be a T-cell-mediated inflammatory disorder, even though its pathogenesis is not fully understood. Inflammation is considered to produce disturbances of lipid metabolism such as an increase in serum triglycerides or decrease in high-density lipoprotein cholesterol. These lipid disturbances caused due to chronic inflammation participate in the increase of cardiovascular risk associated with dyslipidemia leading to a poor prognosis and cardiovascular disorders $(6,7)$ Recent studies have found a close association between atrial fibrillation (AF) and inflammation $(6,8)$.

Atrial fibrillation is the most common sustained cardiac arrhythmia with an overall prevalence of $0.5 \%$ in the adult population. The prevalence rises with age, affecting $2 \%-5 \%$ and $8 \%$ of those aged over 70 and 80 years respectively. Atrial fibrillation may be the first manifestation of many forms of heart disease. Atrial fibrillation is associated with significant morbidity and two-fold increase in mortality that are largely attributable to the effects of underlying heart disease and risk of cerebral embolism (9).

One of the currently significant and crucial contribution to the field of non-invasive electrocardiology is considered to be $\mathrm{P}$ wave dispersion (PWD) which is defined as the difference between maximum $P$ wave duration (Pmax) and minimum $P$ wave duration (Pmin) recorded from multiple surface electrocardiograph (ECG) leads. An increase in $P$ wave dispersion demonstrates heterogeneous intra-atrial and inter-atrial conduction and discontinuous asymmetrical and anisotropic propagation of sinus impulses, providing a substrate that favours re-entry mechanisms $(6,8)$.

The estimation of PWD is a reliable, non-invasive and a feasible variable with good reproducibility of intra-atrial and inter-atrial heterogeneity (6) It could be a useful method of identifying patients who are prone to suffer from AF. Several studies have shown that PWD has a 
predictive value for atrial fibrillation in patients with various conditions $(6,10-12)$ Increased PWD is demonstrated as an independent risk factor for developing atrial fibrillation, which is considered to be the most common perpetuated arrhythmia in the general population $(6,10)$ It also increases the relative incidence of cardiovascular disease and mortality and thus decreases quality of life $(6,10)$.

Though studies in the past have revealed an association between psoriasis and PWD $(13,14)$, literature evidence of an association between LP and PWD is insignificant. Only one study done by Sahin $\mathrm{M}$, et al, found that $\mathrm{P}$-wave dispersion increased on the surface electrocardiographic measurements of LP patients (6) There is no literature evidence of any previous studies being carried out that revealed an association between oral LP and P-wave dispersion.

Hence the proposed present study is done to explore the possible relationship of oral LP with atrial fibrillation by the evaluation of $\mathrm{P}$ - wave dispersion and thus an attempt has been made to predict the underlying unidentified risk of developing atrial fibrillation in these patients.

The present study aimed to study the relationship of OLP and Atrial Fibrillation by the evaluation of P-wave dispersion.

\section{Material and Methods}

This study was conducted after obtaining the ethical approval from the Institutional Ethics Committee of Sri Ramachandra University. All patients with a clinical and histopathological diagnosis of OLP between the ages of 18 to 70 years were included in the study. Patients under 18 years of age and over the age of 70 years were excluded from the study. Patients with known cardiovascular disease, acute/chronic respiratory disease, chronic kidney disease, chronic liver disease, muscular dystrophy or other musculoskeletal disorders, cerebrovascular disease/accident, endocrine disorders, sleep apnea, rheumatoid arthritis, scleroderma, chronic dermatological disorders (psoriasis), haemodialysis, neurological disease, patients with other diseases overlapping with a risk of subclinical or clinical cardiovascular disorder such as diastolic dysfunction, structural and valvular disease, arrhythmias, pulmonary hypertension, diabetes mellitus, obesity, hyperthyroidism, patients on any other systemic medications, patients with a history of smoking and alcoholism and patients not willing to consent were also excluded from the study.

\section{Methodology}

Forty-five OLP patients (Group P) and forty-five age and gender-matched healthy controls (Group C) were included in this clinical study. All subjects provided presenting complaints, detailed medical histories, including the illness history, previous drug usage (including gold salts, beta blockers, thiazide diuretics, furosemide, spironolactone, antimalarials, penicillamine, antihypertensives, nonsteroidal anti-inflammatory drugs and tetracycline) and underwent clinical examinations. None of the patients were on treatment for systemic diseases at the time of investigation (6) Patients diagnosed clinically with OLP underwent an incisional biopsy to histopathologically confirm the diagnosis.

Every subject in Group P and Group C were subjected to the following investigations:

1. Systolic and diastolic blood pressures were measured after a 5-min rest and again 10 min later, the mean value of both measurements was used.

2. The following levels were determined in samples collected between 8 and 9 AM after a 12-h fasting period:

- Fasting and postprandial blood glucose levels

- Complete blood count

- 12- hour fasting lipid profile

- Thyroid profile

- Liver and renal function tests

Twelve-lead electrocardiogram and P-wave duration analysis

Twelve-lead ECGs were obtained after a 10-min rest in a supine position with $20-\mathrm{mm} / \mathrm{mV}$ amplitude and $50-$ $\mathrm{mm} / \mathrm{s}$ rates with standard lead positions using commercially available machinery (MAC 500 GE Medical Systems). The point at which the first atrial deflection crossed the isoelectric line was defined as the beginning of the P-wave and the point at which the atrial deflection returned to the isoelectric line was defined as the end of the P-wave. The Pmax and Pmin were calculated in all 12 leads on the ECG and the difference was defined as P-wave dispersion (11). All measurements were performed after being blinded to the patient's clinical status. The measurements were obtained manually with the help of divider, scale and a magnifying glass to define the electrocardiographic deflection (Fig. 1).

\section{Statistic Analysis}

After the P wave dispersion was recorded, the results were statistically analyzed using SPSS 16.0 version. To describe about the data descriptive statistics mean and Standard Deviation (SD) were used.

\section{Results}

The OLP group (Group P) consisted of 36 females and 9 males with a mean age of 41.3 years and the control group (Group C) consisted of 38 females and 7 males with a mean age of 38.3 years. The results were calculated using Independent t-test.

In Group $\mathrm{P}$ the minimum value of maximum $\mathrm{P}$ wave duration (Pmax) is $80 \mathrm{~ms}$ and maximum value is $140 \mathrm{~ms}$. 
The minimum value of minimum $\mathrm{P}$ wave duration (Pmin) is $40 \mathrm{~ms}$ and maximum value is $60 \mathrm{~ms}$. The minimum value of $\mathrm{P}$ wave dispersion (PWD) is $40 \mathrm{~ms}$ and maximum value is $80 \mathrm{~ms}$. The mean value of Pmax was $110.67 \mathrm{~ms}$ with SD 11.75. The mean value of Pmin was 55.56 ms with SD 9.42. The mean value of PWD was $55.11 \mathrm{~ms}$ with standard deviation 12.17 (Table 1).

In Group C, The minimum value of $\mathrm{P}$ max is $80 \mathrm{~ms}$ and maximum value is 120 . The minimum value of $P$ min is 40 and maximum value is 80 . The minimum value of PWD is 20 and maximum value is 60 . The mean value of Pmax is 98.22 ms with SD 9.36. The mean value of Pmin is 60.00 ms with SD 11.28. The mean value of PWD is $38.22 \mathrm{~ms}$ with SD 10.28 (Table 1).

The mean values of PWD with standard deviation for the Group P and Group C were compared using Student's Independent t-test and the $p$ value was calculated. It is $<0.001$ which is statistically highly significant (Table 1).

\section{Discussion}

The present study was conducted to evaluate $\mathrm{P}$ wave dispersion (PWD) in patients who are clinically and histopathologically diagnosed as OLP as PWD has been proven to be a reliable method with a sensitivity of $83 \%$ and specificity of $85 \%$ and a positive predictive accuracy of $89 \%$ to identify patients who are at risk of atrial fibrillation (AF) $(6,11)$ and also has been shown to have a significant association with OLP (11).

Though the association of oral diseases with various systemic diseases has been proven beyond doubt, the prediction of AF in OLP patients has not been studied extensively in spite of some scanty reports suggesting the same (6) Various inflammatory markers including cytokines like IL-6, TNF-alpha, IL-10, IL-4 and increased oxidative stress are important mediators in the causation of a

Table 1. Mean values (ms) and standard deviation of Pmax, Pmin and PWD in Group P and Group C

\begin{tabular}{ccccc}
\hline & Group P $(\mathrm{n}=45)$ & Group C $(\mathrm{n}=45)$ & t-value & $\mathrm{p}$-value \\
\hline Pmax & $110.67 \pm 11.75$ & $98.22 \pm 9.364$ & - & - \\
Pmin & $55.56 \pm 9.42$ & $60.00 \pm 11.282$ & - & - \\
PWD & $55.11 \pm 12.17$ & $38.22 \pm 10.289$ & 7.107 & $<0.001$
\end{tabular}
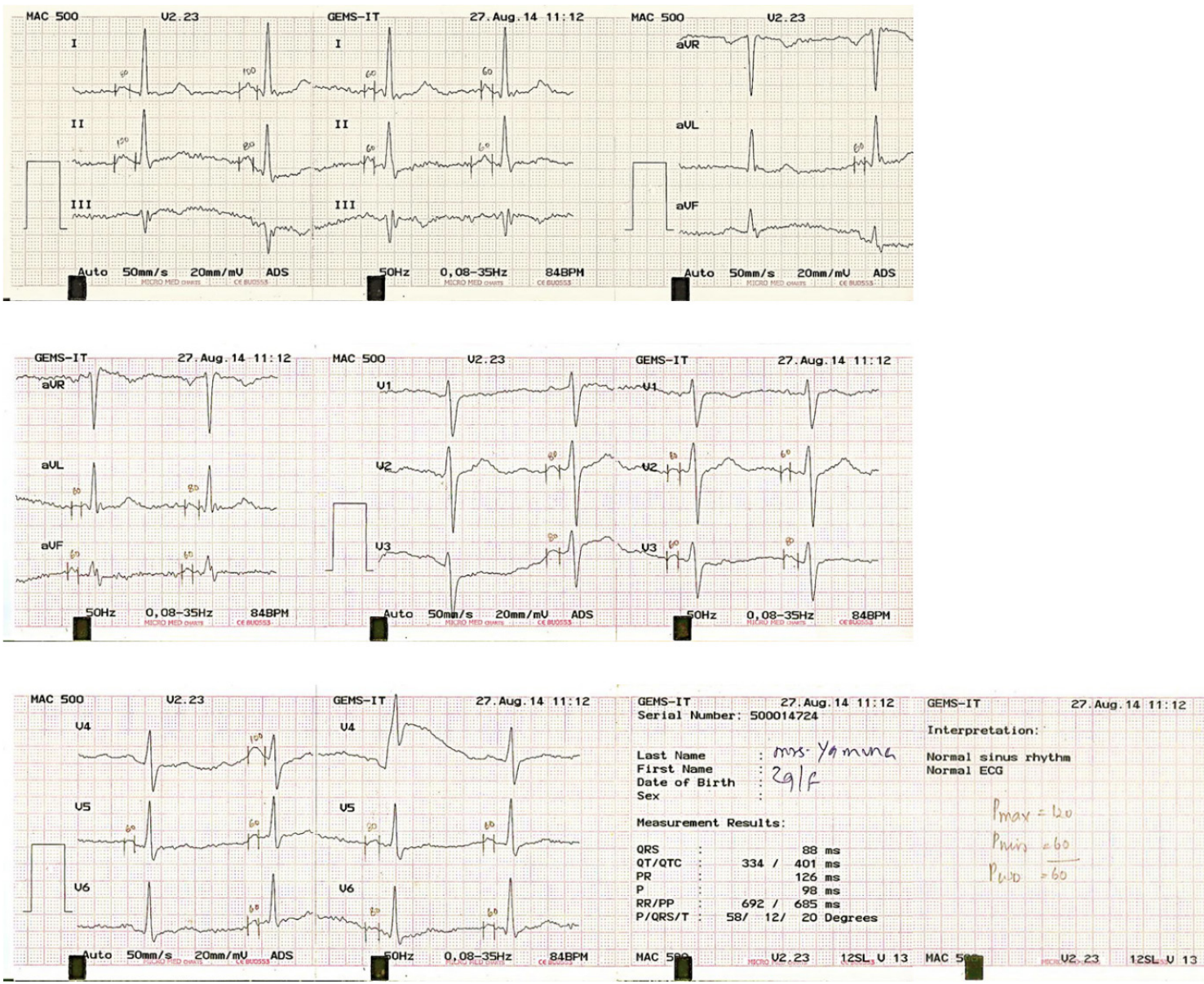

Figure 1. Electrocardiograph depicting P-Wave Dispersion. 
variety of cardiovascular disorders such as atherosclerosis, dyslipidaemia, arrhythmias, stroke, chronic heart failure $(6,15-17)$ Similarly, various cytokines including IL-2, IL-4, IL-6, IL-10, TNF-alpha, IF- alpha, IF- gamma and TGF-beta, increased oxidative stress and reactive oxygen species are involved in the pathogenesis of LP (18) This similarity and association has not been studied extensively and hence has been investigated in the present study.

The study conducted by Sahin M et al., had demonstrated a prolonged PWD in LP patients without other conditions that could increase the PWD such as coronary artery disease, systolic heart failure, hypertension, arrhythmia, antiarrhythmic treatment, obesity, valve disease, pulmonary hypertension, sleep apnea syndrome, chronic obstructive lung disease and neurological disease (6) Similarly, in the present study the patients with above conditions were excluded. Additionally, a few more conditions that have been reported to cause a prolongation of PWD such as chronic renal disease (19), patients undergoing hemodialysis (20), chronic liver disease (19), patients with history of alcohol intake (19), diabetes mellitus (21), rheumatoid arthritis (22), scleroderma (23), psoriasis (13), anemia (24), hyperthyroidism (19) and patients with history of smoking (19) were excluded, thus broadening the exclusion criteria which was not done in the previous study.

Similar to a previous study (6), in the present study PWD was calculated manually on the ECG. Though digitized methods are of better accuracy, manual method of calculation has been reported in various studies to measure PWD to the hundredth of a millisecond (19).

Various studies on $\mathrm{P}$ wave indices in patients with variety of cardiac and non-cardiac conditions have been reported in the literature which comprised of matched normal individuals serving as controls and the PWD in these studies in the controls ranged from $28.0 \pm 7.0$ (10) to $52.1 \pm 2.0 \mathrm{~ms}$ (25). The largest identified community study among the healthy Greek population, demonstrated a mean PWD of 38.4 ms (20). In the Turkish population, PWD was extensively studied and of the various studies the value of PWD in the referent healthy controls ranged from 20.0 to $45.6 \mathrm{~ms}$. $(23,24,26)$. A study conducted in Cuba reported a PWD of $40.0 \pm 12$ ms among the healthy controls (27) and another study in Cuba had a reference value of PWD as $38.0 \pm 10.0 \mathrm{~ms}$ (28). A study conducted among the Chinese demonstrated the average PWD in healthy subjects as $28.9 \pm 10.7 \mathrm{~ms}$ (29). Despite the volume of studies, P wave indices reference ("normal") values have not been standardized (19).

In the absence of a standardized value of PWD, the result obtained from present study when compared to the above mentioned studies, it was noted that the mean PWD of the controls which was $38.2 \pm 10.28$ ms was matching with the mean PWD of the largest identified community study among healthy Greek which was reported as $38.4 \mathrm{~ms}$ (20). It was also similar to the studies conducted among the Cuban population $(40.0 \pm 12)(28)$ and the Chinese population ( $28.9 \pm 10.7 \mathrm{~ms})(29)$.

The mean value of PWD of the patients with OLP in the present study was $55.11 \pm 12.17 \mathrm{~ms}$. This value was greater than the value of mean PWD in OLP patients in the study conducted by Sahin M et al. (6), which was $39.9 \pm 12.9$ ms possibly due to the level and extent of inflammation which is higher in OLP than cutaneous LP since cutaneous LP is self-limiting whereas OLP is chronic and may persist up to 25 years (1) and rarely undergoes spontaneous remission and is a potential source of significant morbidity (30).

Although patients with 5 different clinical manifestation of OLP were enrolled in the study, no subgroups were formed to categorize the clinical types of OLP in the present study to evaluate and compare the significant difference of PWD between them.

The lack of evidence of a reference value of PWD in healthy individuals and the limited sample size are the limitations to the present study. A large population based study is necessary to determine a standardized reference value for healthy individuals. However, the reference value that was obtained in our study controls is comparable to the value obtained among the healthy Asian population, which may be considered as a reference value for future studies (29).

Various factors and conditions have been attributed to cause AF and OLP could also be considered as a potential risk factor for $A F$. The present study necessitates the need for evaluation of the presence of AF in patients with OLP who are otherwise asymptomatic in relation to cardiac conditions.

The present study showed that PWD increased on surface ECG measurements in otherwise asymptomatic OLP patients. The $p$ value obtained was $<0.001$ which was highly significant and was in agreement with a previous study (6), in which PWD was significantly higher in LP patients than in the healthy controls.

The value obtained from the healthy controls though may not be a true reflection of PWD of this population, it is comparable to the value obtained in the Asian population and henceforth may be considered as a reference value for future studies. In spite of the limited sample size, the result of the present study indicates a possibility of occurrence of AF in an otherwise asymptomatic patients with OLP and hence emphasizes the need for evaluating cardiovascular disease particularly atrial fibrillation in patients with OLP using PWD.

Thus the present study suggests a highly statistically 
significant association of OLP with increased PWD and hence it can be construed that OLP may be a potential risk factor for causing AF. Hence the patients with OLP should undergo cardiac evaluation and follow up for early detection of AF. However, the study also suggests the need for further evaluation in a larger sample for the association of OLP with atrial fibrillation.

\section{Resumo}

0 líquen plano oral (LPO) é considerado um distúrbio inflamatório mediado por células T. Acredita-se que a inflamação produza distúrbios do metabolismo lipídico que podem afetar o miocárdio. Uma dispersão de onda-P (DOP) aumentada é demonstrada como um fator de risco independente para o desenvolvimento de fibrilação atrial. Assim, o presente estudo foi conduzido para explorar a possivel relação de LPO com fibrilação atrial pela avaliação por meio de DOP. Eletrocardiogramas (ECG) de 12 derivações foram obtidos de 45 pacientes com LPO e 45 controles saudáveis com idade e sexo equiparados. As durações das ondas P (Pmax e Pmin) foram calculadas em todas as 12 derivações. A diferença entre Pmax e Pmin foi definida como DOP e os valores analisados estatisticamente. 0 estudo mostrou que DOP aumentada nos ECG de superficie dos pacientes com OLP que eram assintomáticos em relação a condições cardiacas. 0 valor p obtido foi $<0,001$, altamente significativo. 0 presente estudo sugere uma associação altamente significativa estatisticamente entre OLP a DOP aumentada. Assim, os pacientes com OLP devem ser submetidos a avaliação cardíaca e acompanhamento para detecção precoce da fibrilação atrial.

\section{References}

1. Rajendran R. Oral lichen planus. J Oral Maxillofac Pathol 2005;9:3-5.

2. Pindborg JJ, Reichart PA, Smith CJ, Van der Waal I. World Health Organization International Histological Classification of Tumours. Histological typing of cancer and precancer of the oral mucosa. Berlin: Springer, 1997.

3. Krutchkoff DJ, Cutler L, Laskowski S. Oral lichen planus. J Oral Pathol Med 1978;7:1-7.

4. Gorouhi F, Davari P, Fazel N: Cutaneous and mucosal lichen planus: a comprehensive review of clinical subtypes, risk factors, diagnosis, and prognosis. Sci World J 2014;742826

5. Scully C, Beyli M, Ferreiro MC, Ficarra G, Gill Y, Griffiths M, et al.., Update on oral lichen planus: etiopathogenesis and management. Crit Rev Oral Biol Med 1998;9:86-121.

6. Sahin M, Bilgili SG, Simsek H, Akdag S, Akyol A, Gumrukcuoglu HA, et al.. Increased $\mathrm{P}$-wave dispersion in patients with newly diagnosed lichen planus. Clinics 2013;68:846-850.

7. Arias-Santiago $S$, Buendia-Eisman $A$, Aneiros-Fernandez J, Girón-Prieto MS, Gutiérrez-Salmerón MT, Mellado VG, et al.. Cardiovascular risk factors in patients with lichen planus. The Am J Med 2011;124:543-548.

8. Turgut O, Tandogan I, Yilmaz MB, Yalta K, Aydin 0. Association of $P$ wave duration and dispersion with the risk for atrial fibrillation: practical considerations in the setting of coronary artery disease. Int J Cardiol 2010;144:322-324.

9. Colledge NR, Walker BR (editors). Davidson's Principles and Practice of Medicine, 21st edition. Edinburgh. Churchill Livingston Elsevier. pp.561-563.

10. Dilaveris PE, Gialafos EJ, Sideris SK, Theopistou AM, Andrikopoulos GK, Kyriakidis M, et al.. Simple electrocardiographic markers for the prediction of paroxysmal idiopathic atrial fibrillation. Am Heart J 1998;135:733-738.

11. Dilaveris PE, Gialafos JE. P-Wave dispersion: a novel predictor of paroxysmal atrial fibrillation. Ann Noninvasive Electrocardiol 2001;6:159-165.

12. Ishida $K$, Hayashi $H$, Miyamoto $A$, Sugimoto $Y$, Ito $M$, Murakami $Y$, et al.. P wave and the development of atrial fibrillation. Heart Rhythm. 2010;7:289-294

13. Bacaksiz A, Erdogan E, Tasal A, Vatankulu MA, Kul S, Sevgili E, Ertas $G$, et al.. Electrocardiographic P-wave characteristics in patients with psoriasis vulgaris. UPS J Med Sci 2012;118:35-41.

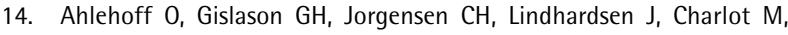
Olesen $\mathrm{JB}$, et al.. Psoriasis and risk of atrial fibrillation and ischaemic stroke: a Danish Nationwide Cohort Study. Eur Heart J 2012;33:20542064.

15. Bermudez EA, Rifai N, Buring J, Manson JE, Ridker PM. Interrelationships among circulating interleukin-6, c-reactive protein, and traditional cardiovascular risk factors in women. Arterioscler Thromb Vasc Biol. 2002;22:1668-1673.

16. Pearson TA, Mensah GA, Alexander RW, Anderson JL, Cannon RO 3rd,

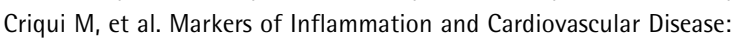
Application to Clinical and Public Health Practice: A Statement for Healthcare Professionals from the Centers for Disease Control and Prevention and the American Heart Association. Circulation 2003;107:499-511.

17. Cesari M, Penninx BW, Newman AB, Kritchevsky SB, Nicklas BJ, SuttonTyrrell $\mathrm{K}$ et al. Inflammatory markers and onset of cardiovascular events: Results from the Health ABC Study. Circulation 2003;108:23172322.

18. Dreiher J, Shapiro J, Cohen AD. Lichen planus and dyslipidaemia: a case control study. The British journal of dermatology. 2009;161:626-629.

19. Magnani JW, Williamson MA, Ellinor PT, Monahan KM, Benjamin EJ. P Wave Indices: Current status and future directions in epidemiology, clinical and research applications. Circ Arrhythm Electrophysiol. 2009;2:72-79.

20. Szabo Z, Kakuk G, Fulop T, Mátyus J, Balla J, Kárpáti I, et al.. Effects of haemodialysis on maximum $\mathrm{P}$ wave duration and $\mathrm{P}$ wave dispersion. Nephrol Dial Transplant 2002;17:1634-1638.

21. Yazici M, Ozdemir K, Altunkeser BB, Kayrak M, Duzenli MA, Vatankulu $M A$, et al.. The effect of diabetes mellitus on the $P$ wave dispersion. Circ J 2007;71:880-883.

22. Guler H, Seyfeli E, Sahin G, Duru M, Akgul F, Saglam H, et al.. P wave dispersion in patients with rheumatoid arthritis: its relation with clinical and echocardiographic parameters. Rheumatol Int 2007;27:813-818.

23. Aktoz M, Yilmaztepe M, Tatli E, Turan FN, Umit EG, Altun A. Assessment of ventricular and left atrial mechanical functions, atrial electromechanical delay and $\mathrm{P}$ wave dispersion in patients with scleroderma. Cardiol J 2011;18:261-269.

24. Simsek H, Gunes Y, Demir C, Sahin M, Gumrukcuoglu HA, Tuncer M. The effects of iron deficiency anemia on $\mathrm{P}$ wave duration and dispersion. Clinics 2010;65:1067-1071.

25. Yigit Z, Akdur H, Ersanli M, Okcun B, Guven 0. The effect of exercise to $P$ wave dispersion and its evaluation as a predictor of atrial fibrillation. Ann Noninvasive Electrocardiol 2003;8:308-312.

26. Can I, Aytemir K, Demir AU, Deniz A, Ciftci O, Tokgozoglu L, et al.. P-wave duration and dispersion in patients with obstructive sleep apnea. Int J Cardiol 2009;133: e85-e89.

27. Carmona Puerta R, Leon Aliz E, López-Calleja MAR, Ramírez RR, Padrón Peña G. Increased $P$ wave dispersion in elite athletes. Indian Pacing and Electrophysiol J 2011;11:73-80.

28. Carmona Puerta R, Ramos Martin R, López-Calleja MAR, Monzón León J, Pérez González L, Castro Torres Y, et al. Increased P wave dispersion in high performance soccer players and its relationship with sport practice time. CorSalud 2013;5:155-160.

29. C Wang, Z Xie, M Li, P Lin, M Cao, Y Xue, et al.. P wave duration and its spatial dispersion in healthy subjects. Int J Cardiovasc Res 2001;1.

30. Eisen D. The clinical features, malignant potential, and systemic associations of oral lichen planus: A study of 723 patients. J Am Acad Dermatol 2002:46:207-214. 